\title{
GAMBARAN PENGETAHUAN PREMENOPAUSE TENTANG PERUBAHAN FISIK DALAM MENGHADAPI MASA MENOPAUSE DI DUSUN MANNYOI DESA TAMANNYELENG KECAMATAN BAROMBONG KAB. GOWA
}

.Overview Of Premenopause's Knowledge About Physical Changes In Facing Menopause Period In Dusun Mannyoi Village Tamannyeleng Barombong Gowa

\author{
Agustina Ningsi ${ }^{1}$, Sitti Mukarramah ${ }^{2}$, Sukmayanti ${ }^{3}$ \\ Poltekkes Kemenkes Makassar \\ *) agustina_ningsih@poltekkes-mks.ac.id phone 081355878497
}

\begin{abstract}
Changes that occur during menopause, women experience a peak complaint while in the post-menopausal phase of this period lasts 6-7 years after menopause. At this time estrogen levels after the low point in accordance with the state of the art and accompanied by the deterioration of body condition. This study aims to determine the characteristics of respondents and description of premenopausal knowledge about physical changes in the face of menopause In Mannyoi Village Tamannyeleng Village District Barombong Gowa District. Samples were taken from primary data, all mothers aged 40 to 55 years old in Mannyoi Village Tamannyeleng Village Barombong District of Gowa regency that fit the criteria in sampling, during the period of February to May 2018, the type of research is descriptive with the method used is through a questionnaire with cross sectional approach, with a sample size of 50 respondents. Characteristics of respondents based on the level of education is elementary education of 41 respondents (82\%), SMP of 8 respondents (16\%) and the high school education of 1 respondent (2\%) and characteristics of respondents by age, 4049 years age of $3774 \%$ ) and age 50 years at 13 (26\%). Good knowledge as many as 34 people (68\%), while knowledgeable enough as much as 9 people (18\%) and who have less knowledge as much as 7 people (14\%). One of the main concerns of mother's knowledge is the intervention of health workers and information from the surrounding community
\end{abstract}

Keywords: Knowledge, Premenopause; physical changes

\section{ABSTRAK}

Perubahan yang terjadi selama berlangsungnya menopause, wanita mengalami keluhan memuncak sementara pada fase sesudah menopause masa ini berlangsung mulai 6-7 tahun sesudah menopause. Pada saat ini kadar estrogen sesudah pada titik rendah sesuai dengan keadaan senium dan disertai dengan mulai memburuknya kondisi badan. Penelitian ini bertujuan untuk mengetahui karakteristik responden dan gambaran pengetahuan premenopause tentang perubahan fisik dalam menghadapi masa menopause Di Dusun Mannyoi Desa Tamannyeleng Kecamatan Barombong Kabupaten Gowa. Sampel diambil dari data primer, seluruh ibu yang berusia 40 sampai 55 tahun di Dusun Mannyoi Desa Tamannyeleng Kecematan Barombong Kabupaten Gowa yang sesuai dengan kriteria dalam pengambilan sampel, selama periode Februari sampai Mei 2018, jenis penelitian adalah deskriptif dengan metode yang digunakan yaitu melalui kuesioner dengan pendekatan cross sectional, dengan jumlah sampel 50 responden. Karakteristik responden berdasarkan tingkat pendidikan yaitu pendidikan SD sebesar 41 responden (82\%), SMP sebesar 8 responden $(16 \%)$ dan yang perpendidikan SMA sebesar 1 orang responden $(2 \%)$ dan karakteristik responden berdasarkan umur yaitu umur 40-49 tahun sebesar $37(74 \%)$ dan umur $>50$ tahun sebesar $13(26 \%)$. Pengetahuan baik sebanyak 34 orang (68\%), sedangkan yang berpengetahuan cukup sebanyak 9 orang (18\%) dan yang memiliki pengetahuan kurang sebanyak 7 orang (14\%). Salah satu yang menpengerahui pengetahuan ibu ialah intervensi dari tenaga kesehatan dan informasi dari masyarakat sekitar

\section{Kata Kunci : Perubahan Fisik, Pengetahuan, Premenopause}

\section{PENDAHULUAN}

Perubahan pengeluaran hormon menyebabkan berbagai perubahan fisik maupun psikologis bagi wanita. Sebagian besar wanita merasa gelisah saat menghadapi masa-masa menopause, sehingga banyak masalah yang sederhana menjadi hal yang begitu besar dan bahkan bisa membuat putus asa seorang wanita saat menghadapi menopause.

Pada masa sebelum menopause klimakterium kira-kira dimulai 6 tahun sebelum masa menopause. Disini, fungsi organ reproduksinya mulai turun, kadar 
estrogen mulai turun dan kadar hormon gonadotropin mulai meningkat sampai timbulnya keluhan tandatanda menopause dan selama berlangsungnya menopause, rentangan 1-2 tahun sebelum sampai 1 tahun sesudah menopause.

Pada periode selama berlangsungnya menopause wanita mengalami keluhan memuncak sementara pada fase sesudah menopause masa ini berlangsung mulai 6-7 tahun sesudah menopause. Pada saat ini kadar estrogen sesudah pada titik rendah sesuai dengan keadaan senium dan disertai dengan mulai memburuknya kondisi badan.

Perubahan yang terjadi dapat berupa terjadinya penurunan kadar estrogen dan kadar gonadotropin mulai meningkat, organ reproduksi mulai mengalami penurunan fungsi: ovarium mengecil, uterus mengecil, epitel vagina menipis, jumlah folikel menjadi hanya beberapa ribu buah saja dan lebih resisten terhadap rangsangan gonadotropin, pada usia 40 tahun lebih siklus haid mulai tidak disertai dengan ovulasi, terjadi perubahan kesuburan seorang wanita mulai menurun pada awal Klimakterium, perubahan perdarahan pada premenopause, pasca menopause terjadi gangguan fisik dan psikis.

Pada masa ini sangat kompleks bagi wanita karena berkaitan dengan keadaan fisik dan kejiwaannya. Selain wanita mengalami stres fisik dapat juga mengalami stres psikologi yang mempengaruhi keadaan emosi dalam menghadapi hal normal sebagaimana yang dialami semua wanita. Perubahan fisik ini dapat berupa hot flushes, keringat malam yang banyak, menstruasi tidak teratur sampai tidak terjadi lagi, mudah tersinggung, mudah lelah, daya ingat menurun, serta nyeri saat senggama, Sedangkan perubahan psikis yang terjadi adalah sikap mudah tersinggung (Lestari:2015).

Menurut Direktur Bina kesehatan Jiwa kementerian Kesehatan, Eka Viora dalam majalah Tempo (2013) usia harapan hidup masyarakat Indonesia pada tahun 2014 rata-rata akan mencapai 72 tahun, pada perempuan angka harapan hidup ini lebih besar, bisa lima tahun lebih tinggi. Peningkatan angka harapan hidup ini menyebabkan bertambahnya populasi penduduk wanita (Sufa, 2013).

Badan Kesehatan World Health Organization (WHO) memperkirakan usia harapan hidup orang Indonesia adalah 75 tahun pada tahun 2025. Hal ini berarti wanita memiliki kesempatan untuk hidup ratarata 25 tahun lagi sejak awal menopause. Data dari WHO tahun 2013 jumlah wanita di dunia yang memasuki fase menopause diperkirakan mencapai 1,42 milyar orang. Jumlah wanita menopause di Indonesia tahun 2013 sebanyak 15,5 juta orang bahkan pada tahun 2025 diperkirakan akan ada 60 juta wanita mengalami menopause (WHO : 2013)

Berdasarkan data dari Badan Pusat Statistik (BPS) tahun 2000 jumlah wanita Indonesia mencapai
14,4 juta jiwa dan pada tahun 2020 diprediksi meningkat mencapai 28.822 .879 jiwa (Nugroho, 2008). Meningkatnya jumlah penduduk wanita tersebut berpengaruh terhadap jumlah dan proporsi penduduk perempuan yang memasuki usia menopause dimana setiap tahunnya mengalami peningkatan yang sangat signifikan. Setiap tahunnya 2 sekitar 25 juta wanita diseluruh dunia mengalami menopause dan diperkirakan meningkat dari 500 juta pada tahun 2015 menjadi lebih dari 1 milyar pada tahun 2030.

Berdasarkan data dalam Profil Kesehatan Provinsi sulawesi selatan 2014 dalam data penduduk tahun 2014 memperkirakan jumlah penduduk wanita yang berusia 45-64 tahun sebanyak 580.999 jiwa.

Berdasarkan data profil kesehatan 2014 Di Kabupaten Gowa memperkirakan jumlah penduduk wanita yang berusia 15-64 tahun sebanyak $63,25 \%$ (215.554 jiwa). Data proyeksi penduduk wanita pada Kecamatan Barombong sendiri yaitu mencapai 34.931 jiwa. Data tahun 2017 jumlah wanita premenopause di Dusun Mannyoi Desa Tamannyeleng Kecamatan Barombong Kabupaten Gowa sebanyak 102 orang (Sumber data statistik: 2017)

Wanita memiliki angka harapan hidup ini lebih besar, bisa lima tahun lebih tinggi. Peningkatan angka harapan hidup ini menyebabkan bertambahnya populasi penduduk wanita. Meningkatnya jumlah penduduk wanita tersebut berpengaruh terhadap jumlah dan proporsi penduduk perempuan yang memasuki usia menopause.

Sehingga hal ini akan mempengaruhi sikap dan perilaku hidup sehat serta dalam menanggulangi masalah yang kurang dimengerti mengenai sikap dalam menghadapi menopause. Begitu juga dalam kehidupan sehari-hari banyak wanita yang belum memahami bagaimana harus bersikap dalam menghadapi menopause.

Perubahan-perubahan ini dialami manusia secara bertahap. Masa menopause ditandai dengan masa transisi berhentinya fungsi reproduksi, tetapi secara biologis menopause berarti berhentinya menstruasi yang dapat menyebabkan berbagai perubahan fisik. Perubahan pada fisik antara lain: perubahan distribusi lemak tubuh yang mana pada wanita menopause lemak akan menumpuk pada pinggul dan perut, perubahan tekstur kulit, dan terkadang disertai dengan jerawat.

Beberapa penelitian telah membuktikan bahwa tekanan psikis yang timbul dari nilai sosial mengenai wanita yang menopause memberikan kontribusi terhadap gejala fisik selama periode menopause. Gejala fisik yang dirasakan dapat memicu munculnya masalah psikis. Perasaan yang biasa muncul pada fase ini antara lain rapuh, sedih dan tertekan. Akibatnya wanita pada masa menopause menjadi 
depresi, tidak konsentrasi bekerja dan mudah tersinggung (Pudiastuti, 2012).

Dari uraian dan pengamatan peneliti di atas, peneliti tertarik untuk melakukan penelitian tentang "Gambaran Pengetahuan Premenopause Tentang Perubahan Fisik Dalam Menghadapi Masa Menopause" Di Dusun Mannyoi Desa Tamannyelang Kecamatan Barombong Kabupaten Gowa, karena warga di daerah tersebut masih banyak yang belum ada kesiapan untuk menghadapi masa menopause.

Tujuan Penelitian

Untuk mengetahui gambaran pengetahuan premenopause tentang perubahan fisik dalam menghadapi masa menopause di Dusun Mannyoi Desa Tamannyeleng Kecematan Barombong Kabupaten Gowa .

\section{METODE}

Penelitian ini merupakan penelitian deskriptif yaitu penelitian yang dilakukan untuk mendiskripsikan pengetahuan premenopause tentang perubahan fisik dalam menghadapi masa menopause di Dusun Mannyoi Desa Tamannyeleng Kecematan Barombong Kabupaten Gowa.

Penelitian dilaksanakan di Dusun Mannyoi Desa Tamannyeleng Kecematan Barombong Kabupaten Gowa, penelitian dilaksanakan pada bulan Februari Mei 2018.

Populasi dalam penelitian ini adalah seluruh ibu yang memasuki masa premanopause di Dusun Mannyoi Desa Tamannyeleng Kecematan Barombong Kabupaten Gowa berjumlah 102 orang. Sampel dalam penelitian ini adalah seluruh ibu yang berusia 40-55 tahun di Dusun Mannyoi Desa Tamannyeleng Kecamatan Barombong Kabupaten Gowa yang sesuai dengan kriteria dalam pengambilan sampel sebanyak 50 responden.

Pengumpulan data dilakukan sendiri oleh peneliti dengan cara membagikan kusioner kepada responden.

Observasi

Teknik ini digunakan dengan mengadakan pengamatan langsung pada objek-objek tertentu, kejadian,dan proses untuk mendapatkan informasi dari objek yang diteliti sehubungan dengan permasalahan yang dikaji dan diproses untuk mengetahui tentang Gambaran Pengetahuan Premenopause Tentang Perubahan Fisik Dalam Menghadapi Masa Menopause Di Dunu Mannyoi Desa Tamannyeleng Kecamatan Barombong Kabupaten Gowa.

Angket

Angket dipergunakan untuk mendapatkan sebagian besar data yang dibutuhkan dari responden tentang Gambaran Pengetahuan Premenopause Tentang Perubahan Fisik Dalam Menghadapi Masa Menopause Di Dusun Mannyoi Desa Tamannyeleng
Kecamatan Barombong Kabupaten Gowa. Jumlah responden berjumlah 50 orang, dimana dari semua responden merupakan ibu yang berusia 40-55 tahun dan ibu yang masih menstruasi.

Dokumentasi

Teknik ini digunakan dalam memperoleh sejumlah data melalui pencatatan dari sejumlah dokumen atau bukti tertulis seperti keadaan populasi, struktur organisasi, data, dan sebagainya.

HASIL

Berdasarkan hasil penelitian yang telah dilaksanakan di Dusun Mannyoi Desa Tamannyeleng Kecamatan Barombong Kabupaten Gowa. Periode Februari sampai Mei tahun 2018 ditentukan pengambilan sampel dengan cara random sampling, sebanyak 102 orang populasi ditentukan sample dengan rumus solving yaitu sebanyak 50 orang.

Penelitian ini dilakukan untuk mendeskripsikan pengetahuan, dengan menggunakan kuesioner. Data yang telah dikumpulkan diperiksa kelengkapannya, kemudian hasilnya diuraikan secara sistematis sebagai berikut:

Tabel 1. Distribusi responden berdasarkan pendidikan di Dusun Mannyoi Desa Tamannyelang Kecamatan Barombong Kabupaten Gowa.

\begin{tabular}{|c|c|c|}
\hline $\begin{array}{l}\text { Pendidika } \\
\mathrm{n}\end{array}$ & $\begin{array}{l}\text { Frekuensi } \\
\text { (f) }\end{array}$ & $\begin{array}{c}\text { Persentas } \\
(\%)\end{array}$ \\
\hline SD & 4 & 8 \\
\hline & 1 & \\
\hline SMP & 8 & 1 \\
\hline SMA & 1 & 2 \\
\hline JUMLAH & 50 & 100 \\
\hline
\end{tabular}

Sumber: data primer tahun 2018

Bersdasarkan tabel di atas tingkat pendidikan ibu pendidikan SD sebesar 41 responden (82\%), SMP sebesar 8 responden (16\%) dan yang perpendidikan SMA sebesar 1 orang responden (2\%).

Tabel 2. Distribusi responden berdasarkan umur di Dusun Mannyoi Desa Tamannyelang Kecamatan Barombong Kabupaten Gowa.

\begin{tabular}{ccc}
\hline Umur & $\begin{array}{c}\text { Frekuensi } \\
(\mathrm{f})\end{array}$ & $\begin{array}{c}\text { Persentase } \\
(\%)\end{array}$ \\
\hline 40-49 Tahun & 37 & 74 \\
$>50$ Tahun & 13 & 26 \\
\hline JUMLAH & 50 & 100 \\
\hline \multicolumn{2}{l}{ Sumber: data primer tahun 2018. }
\end{tabular}


Berdasarkan tabel diatas dilihat dari umur responden yakni umur 40-49 tahun sebesar 37 (74\%) dan umur $>50$ tahun sebesar $13(26 \%)$.

Tabel 3. Distribusi responden berdasarkan tingkat pengetahuan tentang perubahan fisik mengenai menopause di Dusun Mannyoi Desa Tamannyelang Kecamatan Barombong Kabupaten Gowa.

\begin{tabular}{lcc}
\hline $\begin{array}{l}\text { Pengetah } \\
\text { uan }\end{array}$ & $\begin{array}{c}\text { Frekuensi } \\
(\mathrm{f})\end{array}$ & $\begin{array}{c}\text { Persentase } \\
(\%)\end{array}$ \\
\hline BAIK & 34 & 68 \\
CUKUP & 9 & 18 \\
KURANG & 7 & 14 \\
\hline JUMLAH & 50 & 100 \\
\hline Sumber: data primer tahun 2018.
\end{tabular}

Berdasarkan tabel di atas tingkat pengetahuan ibu yang baik sebesar $34(68 \%)$, pengetahuan ibu cukup sebesar $9(18 \%)$ dan yang memiliki pengetahuan tidak baik sebesar 7 (14\%).

\section{PEMBAHASAN}

Pengetahuan merupakan hasil dari tahu, dan ini terjadi setelah orang melakukan pengindraan terhadap suatu objek tertentu. Pengindraan terjadi melalui pancaindra manusia, yakni indra penglihatan, pendengaran, penciuman, rasa dan raba (Notoatmodjo, 2010). Misalnya pengetahuan ibu tentang perubahan fisik dalam masa menopause seperti keringat berlebihan tengah malam dan adapun disebabkan karena berbagai macam faktor diantaranya yang mempengaruhi pengetahuan menurut Titik Lestari, 2015: Tingkat Pendidikan yaitu, Upaya untuk memberikan pengetahuan sehingga terjadi perubahan perilaku positif yang meningkat. Seseorang yang mendapatkan informasi lebih banyak akan menambah pengetahuannya dan pengalaman adalah sesuatu yang pernah dilakukan seseorang akan menambah pengetahuan tentang sesuatu yang bermanfaat.

Perubahan pengeluaran hormon menyebabkan berbagai perubahan fisik maupun psikologis bagi wanita. Pada masa ini sangat kompleks bagi wanita karena berkaitan dengan keadaan fisik dan kejiwaannya. Selain wanita mengalami stress fisik dapat juga mengalami stress psikologi yang mempengaruhi keadaan emosi dalam menghadapi hal normal sebagaimana yang dialami semua wanita. Perubahan fisik ini dapat berupa hot flushes, keringat malam yang banyak, menstruasi tidak teratur sampai tidak terjadi lagi, mudah tersinggung, mudah lelah, daya ingat menurun, serta nyeri saat senggama.

Berdasarkan hasil analisis data baik secara univariat sebagian wujud pembuktian gambaran yang telah dilakukan, selanjutnya untuk mempertajam analisis tersebut maka dibuat pembahasan sesuai dengan variabel yang diteliti sebagai berikut:

Distribusi responden menurut pendidikan menunjukkan distribusi tertinggi adalah sekolah dasar (SD) sebanyak 41 responden (82\%), sekolah menengah pertama (SMP) sebanyak 8 responden $(16 \%)$ dan sekolah menengah atas (SMA) sebanyak 1 orang responden (2\%). Tingkat pendidikan seseorang berhubungan dengan kemampuan seseorang menerima informasi dan menganalisis dan mengolahnya menjadi suatu pengetahuan. Semakin tinggi tingkat pengetahuan seseorang, maka pengetahuannya cenderung semakin baik.

Hal tersebut sebagaimana dikemukakan oleh Perry \& Potter (2005), menyatakan bahwa tingkat pendidikan dapat meningkatkan pengetahuan tentang kesehatan. Pendidikan merupakan hal yang sangat penting dalam mempengaruhi pikiran seseorang. Seorang yang berpendidikan ketika menemui suatu masalah akan berusaha berfikir sebaik mungkin dalam menyelesaikan masalah tersebut. Orang yang berpendidikan baik cenderung akan mampu berfikir tenang terhadap suatu masalah tetapi kenyataannya di lapangan tidak semua pendidikan mempengaruhi pengetahuan seseorang.

Distribusi responden menurut usia menunjukkan distribusi tertinggi adalah 40-49 tahun sebanyak 37 responden $(74 \%)$ dan sisanya 13 responden $(26 \%)$ berumur $>50$ tahun. Distribusi usia menopause responden ternyata sesuai dengan pendapat Rees (2009) yang menyatakan bahwa menopause (menstruasi terakhir) menandai akhir masa reproduksi seorang wanita dan biasanya terjadi pada wanita berusia antara 40 sampai 55 tahun.

Hasil penelitian yang dilakukan, gambaran pengetahuan ibu yang baik sebesar 34 (68\%), pengetahuan ibu cukup sebesar $9(18 \%)$ dan yang memiliki pengetahuan kurang sebesar 7 (14\%). Salah satu yang mempegaruhi pengetahuan ibu adalah adanya intervensi petugas kesehatan secara langsung terhadap lansia yaitu dengan melakukan kunjungan dan meberikan penyuluhan kepada para ibu-ibu dalam persiapan menghadapi premenapause. Selain itu informasi juga di dapat dari para masyarakat dilingkungan sekitar, yang memiliki pengetahuan lebih terhadap masa premenapause.

Penelitian ini sejalan dengan penelitian yang dilakukan oleh Sasitrn Rakkuea, (2016), hasilnya Distribusi frekuensi pengetahuan tentang menopause menunjukkan distribusi yang tertinggi sebanyak 21 responden $(61,8)$. Menopause umumnya dianggap sebagai hal yang wajar oleh wanita, khususnya wanita-wanita di pedesaan. Pada masa menopause umumnya mereka menyadari bahwa tugas mereka sebagai ibu khususnya proses reproduksi telah selesai dan mereka memfokuskan dirinya untuk 
mendidik anak-anak mereka untuk menjadi keluargakeluarga baru.

Penelitian ini juga sejalan dengan penelitian yang di dilakukan oleh Selvia Hekhmati, (2016), Dari hasil penelitian menunjukan bahwa distribusi perubahan fisik pada wanita menopause yang menempati presentase paling sering dialami responden adalah rasa panas (hot flush) terdapat 61 responden dengan jumlah presentase $81,3 \%$. Hasil penelitian yang dilakukan oleh Thurson (2009), yang mengatakan bahwa keluhan hot flush dapat diredakan dengan pemberian estrogen dalam 6 bentuk terapi efektif. Dalam hasil penelitian Archer (2011), mengatakan bahwa hot flush yang diderita ini biasanya berhubungan dengan cuaca panas dan lembab. Selain itu, juga berhubungan dengan ruang yang sempit, kafein, alcohol, atau makanan pedas. Keluhan hot flush dapat berkurang setelah tubuh menyesuaikan diri dengan kadar estrogen yang rendah.

Banyaknya informasi yang diperoleh seseorang banyak juga pengetahuan seseorang tentang kesehatan, semakin bijak orang tersebut karena banyaknya informasi yang ditemukan tentang perubahan fisik. Seseorang akan bertambah pengetahuannya karena tradisi dan adat istiadat yang sering dilakukan seseorang melalui penalaran apakah yang baik atau buruk untuk mereka. Selain itu ekonomi seseorang mempengaruhi tersedianya fasilitas yang menunjang untuk mendapatkan informasi tentang perubahan fisik dalam masa menopause sehingga dapat mempengaruhi seseorang.

Banyak faktor yang mempengaruhi seseorang untuk mengetahui perubahan fisik tersebut (umur, pendidikan, pengetahuan, sikap) dan faktor pendorong (dukungan petugas kesehatan).

Selama penelitian ini kendala yang dihadapi adalah ketersediaan waktu responden, sehingga peneliti susah menemui responden dan harus berulang.

\section{KESIMPULAN}

Berdasarkan dari hasil penelitian gambaran pengetahuan premenopause tentang perubahan fisik dalam menghadapi masa menopause di Dusun Mannyoi Desa Tamannyeleng Kecamatan Barombong Kabupaten Gowa:

1. Karakteristik responden berdasarkan tingkat pendidikan yaitu pendidikan SD sebesar 41 responden (82\%), SMP sebesar 8 responden $(16 \%)$ dan yang perpendidikan SMA sebesar 1 orang responden $(2 \%)$ dan karakteristik responden berdasarkan umur yaitu umur 40-49 tahun sebesar $37(74 \%)$ dan umur $>50$ tahun sebesar 13 (26\%).

2. Pengetahuan baik sebanyak 34 orang $(68 \%)$, sedangkan yang berpengetahuan cukup sebanyak 9 orang $(18 \%)$ dan yang memiliki pengetahuan kurang sebanyak 7 orang $(14 \%)$. Salah satu yang menpengerahui pengetahuan ibu ialah intervensi dari tenaga kesehatan dan informasi dari masyarakat sekitar.

\section{SARAN}

1. Bagi Petugas Kesehatan

Untuk petugas kesehatan terutama wilayah kerja Puskesmas kanjilo mungkin perlu pengadaan penyuluhan yang berkesinambungan tentang gambaran pengetahuan premenopause tentang perubahan fisik dalam menghadapi masa menopause

2. Bagi Peneliti Lain

Untuk peneliti lain dapat melanjutkan penelitian dengan metode yang berbeda dan dapat dilakukan mengenai sikap dan perilaku premenopause dalam menghadapi masa menopause.

\section{UCAPAN TERIMA KASIH}

Ucapan terima kasih disampaikan kepada semua pihak yang telah memfasilkitasi telaksananya penelitian ini. Khususnya kepada :

1. Direktur Poltekkes Kemenkes Makassar H. agustian Ipa

2. Ketua Jurusan Kebidanan Poltekkes Kemenkes Makassar

3. Aparat pemerintah Desa Tamannyelleng Kecamatan Barombong Kabupaten Gowa

\section{DAFTAR PUSTAKA}

Dinas Kesehatan Sulsel. 2014. Profil Kesehatan Provinsi Sulsel 2014. Dinas Kesehatan Sulsel. (Online), (www.depkes.go.id, diakses 20 Desember 2017)

Dinas Kesehatan Kabupaten Gowa. 2014. Profil Kesehatan Kabupaten Gowa 2014. Dinas Kesehatan Sulsel. (Online), (www.depkes.go.id, diakses 20 Desember 2017)

Francis Catherine. 2017. Melalui Menopause. Jakarta:Libri

Friska, Dkk. 2014. Perubahan Fisik Perilaku Seksual Dan Psikologis Pada Wanita Yang Mengalami Menopause, 
(Online),(http://ejurnal.stikesbaptis.ac.id, diakses pada tanggal 17 oktober 2017, pukul 23:46 Wita)

Hekhmawati, Selvia. 2016. Hubungan Pengetahuan, Sikap Tentang Menopause Dengan Kesiapan Menghadapi Menopause Di Puskesmas Pekanbaru. (Online), (http://doi.org/10.22216/jen.v2i2.1853. Diakses pada tanggal 01 Juli 2018, pukul 13:20 Wita.)

Irianto Koes. 2015. Kesehatan Reproduksi. Bandung: Alfabet cv.

Lestari, Titik. 2015. Kumpulan Teori Untuk Kajian Pustaka Penelitian Kesehatan. Yogyakarta:Nuha Medika.

Nopi, dkk. 2012.Faktor-Faktor Yang Berhubungan Dengan Kecemasan Wanita Dalam Menghadapi Menopause Di Puskesmas Melur Pekanbaru Tahun 2014, (Online), (http://ejournal.stikesaisyah.ac.id,diakses pada tanggal 17 oktober 2017, pukul 23:02 Wita)

Notoatmodjo. 2010. Kumpulan Teori Untuk Kajian Pustaka Penelitian Kesehatan. Yogyakarta:Nuha Medika.

Nurpatminingsih Susanti. 2016. Hubungan Antara Kesiapan Menopause Dengan Kecemasan Menghadapi Menopause Pada Ibu Pkk Di Desa Gentan Kecamatan Bendosari Kabpuaten Sukoharjo, (Online), (http:/leprints.ums.ac.id, diakses pada tanggal 17 oktober 2017, pukul 22:21 Wita)

Rakkuea, sasitorn (2016). Gambaran Pengetahuan Wanita Tentang Menopause Di Dukuh Sorobaon Kelurahan Jati Kecamatan Jaten Kabupaten Karangayar, (Online), (http://eprints.ums.ac.id/46564/18/Naskah\%20publikasi\%20fix.pdf. Diakses pada tanggal 01 Juli 2018, Pukul 13:45 Wita)

Siti Mulyani, Nina. 2013. Menopause akhir siklus menstruasi pada wanita di usia pertegahan. Yogyakarta:Nuha Medika Sugiono. 2011. Metode Penelitian Administrasi. Bandung: Alfabeta cv

Tagliaferri Mary, Dkk. 2006. The New Menopause Book. New York:Indeks

Widyastuti Yani, Dkk. 2014. Kesehatan Reproduksi. Jakarta:CV Trans Info MediaWorld Healt Organization : 2013. (Online), (http://eprints.ums.ac.id. Diakses pada tanggal 28 november 2017 , 